\title{
Embracing Ambiguity in the Analysis of Form in Pop/Rock Music, 1982-1991
}

\author{
Trevor de Clercq
}

KEYWORDS: Form, popular music, rock music, verse, chorus, bridge

ABSTRACT: A central concern for theories of form in pop/rock music is the division of a song into sections and, consequently, the categorization of these sections according to a standard set of section labels. Psychological research on categorization shows that it is inherently a perceptual process, one that involves graded membership and fuzzy boundaries. Thus in contrast to prior theorists, who often attempt to minimize ambiguity in the analysis of form in pop/rock music, I confront ambiguity directly, organizing and describing many of the common types encountered. I focus exclusively on the time period 1982-1991, when verse-chorus form can be considered to have achieved widespread currency. After providing an illustrative exemplar, I discuss three types of ambiguity common to this decade, each based on the main section role involved: 1) verse ambiguity, which typically derives from weak section differentiation; 2) chorus ambiguity, which usually involves a blend of more than one section role; and 3) bridge ambiguity, which often results from different hierarchical meanings of the bridge label.

Received December 2016

Volume 23, Number 3, September 2017

Copyright (C) 2017 Society for Music Theory

\section{Introduction}

[1.1] The analysis of form in pop/rock music traditionally involves partitioning a song into various discrete sections, such as verse, chorus, and bridge. Perhaps unsurprisingly, this process is not always straightforward, since two different analysts sometimes provide two different interpretations of the same song. For example, the form of the U2 song "One" (1991) has been analyzed in at least two different ways, as shown in Example 1a. Endrinal $(2008,148)$ views the song primarily as an alternation of verse and chorus sections, whereas Harris (2006, 98-99) views it primarily as a succession of verse sections only. ${ }^{(1)}$ We may naturally wonder, therefore: What factors underlie this and other instances of disagreement in the analysis of form in pop/rock music?

[1.2] Examining the song "One" more closely, we can find evidence both for and against the readings that Endrinal and Harris offer. ${ }^{(2)}$ On one hand, the passage that Endrinal labels as a 
chorus (Example 1b) sounds rather chorus-like in contrast to the preceding material. Most notably, the melody rises into a higher register along with a corresponding lift in the harmonies to the relative major, which are features that theorists have associated with verse-chorus pairings. ${ }^{(3)}$ On the other hand, there is very little if any textural change between the first eight bars and the second eight, which dampens our sense that these sixteen bars cleave into two separate sections. Another factor involves the lyrics. In particular, many explanations of form in pop/rock music observe that the lyrics of a verse typically change each time its music reappears, whereas the lyrics of a chorus typically do not (e.g., Stephenson 2002, 134-35; Everett 2009, 145). As Example 1c shows, the lyrics for each iteration of Endrinal's chorus section are considerably different, with "one" being the only significant word shared among all four instances of the passage. Overall, therefore, the differences in interpretation observed here appear to derive from conflicting perceptual cues within different domains (harmony, melody, texture, lyrics), each of which has the potential to confirm or contradict a given reading. In short, the form of the song is ambiguous.

[1.3] To some, the lack of agreement on the form of this song may seem like a rare occurrence - too rare to deserve closer attention. Neal, for example, writes that "the mere act of labeling sections of a song is little more than a rote exercise, one that is easily and frequently taught to undergraduate students of popular music" $(2007,44)$, implying that partitioning a song into sections and applying standard form labels is usually a clear-cut process. And it may be so, if done alone. But in my own experience-both in analyzing songs and reading other's analyses - I find form in pop/rock music to be a very subjective topic. (Form in common-practice era music is no different, considering the panoply of approaches that have been offered to describe the form of the first movement of a sonata.) ${ }^{(4)}$ It is impossible to quantify the true extent of subjectivity in the analysis of form in pop/rock music, of course, although some recent work sheds light on the issue. In a study by Bruderer, McKinney, and Kohlrausch (2006), for example, listeners were asked to label structural boundaries in six full-length popular songs. The authors found that, of all the boundaries identified, only a few were agreed upon by all participants. In a similar study by Smith (2014), trained musicians independently labeled structural boundaries in a large and stylistically diverse corpus of recordings. Allowing for one or two bars of leeway, participants agreed on the location of segment boundaries about $77 \%$ of the time. ${ }^{(5)}$ More recently, I examined the extent of section-label agreement in the corpus of rock songs I created with David Temperley (de Clercq 2017). When grouping section labels into general categories (verse, chorus, bridge), I found that our section labels matched $67 \%$ of the time, given any particular moment in the corpus. Thus while analysts may not often wildly disagree on the form of a song (after all, even Endrinal and Harris agree that roughly half of "One" contains verse material), we can expect to regularly find a good deal of variation from one interpretation to another.

[1.4] If structural boundaries and section labels in pop/rock music are often ambiguous, how should a theory of form in pop/rock respond? ${ }^{(6)}$ One approach would be to try and reduce this ambiguity by more strictly defining the standard section labels, taking care to hew to these definitions in analytical practice. Harris, for example, states that the passages Endrinal labels as the chorus in "One" are "clearly not choruses" due to the lack of strict lyric repetition $(2006,98)$. In other words, lyric repetition is an essential quality of a chorus, and without this feature, a section cannot be a chorus. Similarly strict approaches to section categorization can be found in the writing of other theorists. Endrinal himself, for example, writes that the middle passage (around 2:11, Example 2a) of the song "Elevation" (U2, 2000) "cannot be called a 'bridge'" because it lacks transitional function $(2008,78)$. Osborn analyzes "Don't Stop Believin'” (Journey, 1981) in much the same way, stating that while most people would hear the final passage (beginning around 3:21, Example 2b) as the chorus of the song, it is "not a chorus" (emphasis in the original) because it occurs only at the end of the song $(2010,19)$. In each of these cases, the author implies that a particular feature-e.g., lyric repetition, transitional function, recurrence in the song -is an 
essential element for applying a section label. In the field of cognitive psychology, this outlook is commonly referred to as a "classical" categorization scheme (Murphy 2002, 12-16), whereby membership in a category, such as "chorus" or "bridge," is an all-or-nothing affair, hinging on the existence of one or more essential qualities. For both Endrinal and Osborn, this outlook gives rise to the coinage of new section labels, such as "interverse" (Endrinal 2011) and "terminal climax" (Osborn 2013), so as to account for song sections that do not conform to certain aspects of conventional section labels. Our approach to ambiguity, therefore, has the power to shape the analytical systems we devise.

[1.5] An alternative theoretical framework would be to accept the ambiguity of these section labels as an intrinsic part of the analytical process. Indeed, research within the field of cognitive psychology (e.g., Rosch 1973, Rosch 1978, Smith and Medin 1981) has shown that classical categorization - a definition-based approach that relies on essential elements for category membership-does a poor job of modeling the way that humans naturally conceptualize and understand the world around them. ${ }^{(7)}$ Instead, the categories that humans use, and the concepts those categories represent, are better considered to be graded (or fuzzy), with certain members more central than others. Ambiguity, in other words, is not just a fundamental component in the analysis of form in pop/rock music but is fundamental to all mental tasks that involve categorization. For example, the debate among pop/rock theorists about what harmonic entities do or do not qualify as instances of "dominant" is evidence that the categorization of harmonic function is a fuzzy process (see, for example: Doll 2009, Biamonte 2010, Nobile 2016). But although previous authors have conceded that form labels in pop/rock can often be unclear (e.g., Stephenson 2002, 133), no published work has yet closely investigated the types of ambiguity typically encountered and the mechanisms by which these types of ambiguity arise. ${ }^{(8)} \mathrm{I}$ believe this to be an essential task for understanding form in pop/rock music, as I have found that many if not most well-known songs, especially those that have achieved great critical acclaim, involve ambiguous formal structures. In other words, part of the appeal of these songs may derive from the interesting ways in which they manipulate the conventions of form.

[1.6] In this paper, I embrace ambiguity in the analysis of form in pop/rock music, organizing and describing many of the common types of ambiguity that are encountered. As I argue, it is often preferable to adopt a "both/and" approach to section labels rather than the mutually exclusive "either/or" approach that pervades extant published analyses. Admittedly, this methodology is concerned greatly with taxonomy. ${ }^{(9)}$ But as Lakoff and Johnson argue (1980), the words we use significantly affect the way we view the world. I begin my discussion below with an illustrative song example that expresses relatively clear section roles. From this reference point, I move outwards to examine ambiguous moments in verse, chorus, and bridge identity, since these three section roles are the most commonly used in analysis and thus most often participate in sectionrole ambiguity. As I show, the mechanism by which ambiguity occurs often corresponds to the main section role involved: verse ambiguity typically derives from weak section differentiation, chorus ambiguity usually involves a blend of more than one section role, and bridge ambiguity often results from different hierarchical meanings of the "bridge" label.

[1.7] All of the song examples I use are drawn exclusively from the period 1982-1991. I delimit the time frame in this way because the same form label may hold different meanings, and thus evoke different conceptual frameworks, within different historical contexts. We should not expect, for example, the term "bridge" to have the same meaning in popular music of the 1940s, "50s, and early '60s - where it typically refers to the middle passage of an AABA form-as it does in music from the late 1960s, '70s, and '80s - where it more often refers to the middle passage of a versechorus form. I have chosen the particular timespan of 1982-1991 for a number of reasons. For one, we find a shifting of form types during the early years of rock music, as noted in the work of Covach (2006), Summach (2011), and von Appen and Frei-Hauenschild (2015). By the early 1980s, 
however, form types crystallize around the verse-chorus configuration, with verse-chorus forms accounting for arguably all of the \#1 Billboard hits by $1982 .{ }^{(10)}$ This is not to say that other form types did not still exist after 1982, only that the overwhelmingly dominant blueprint for a pop/rock song by 1982 (or thereabouts) was the verse-chorus form. Of course, verse-chorus form continues to be a common scheme for hit songs on the charts of today. In 1992, however, the Billboard charts saw a dramatic increase in rap and dance tracks to high chart positions, and the typical forms used in these newer styles may be somewhat different than the typical forms in pop/rock music from the decade prior; thus I have chosen an end date of 1991.(11)

\section{Prototypes and Exemplars}

[2.1] If we do not understand categories through definitions or essential elements, by what means do we assess category membership? Of the numerous theories that have been proposed (see Murphy 2002), I will focus on just two that I find particularly applicable here: the exemplar view and the prototype view. In the exemplar view, your understanding of the concept of "chorus," for example, involves the set of hundreds or thousands of passages that you have previously judged to be choruses, some of which are more memorable than others (for whatever reason). When you hear a particular passage in a new song, you compare that passage to the set of passages previously judged to be choruses. In contrast, the prototype view posits that your understanding of the concept of "chorus" involves comparison to a summary representation, which is essentially a set of weighted attributes. ${ }^{(12)}$ From a lifetime of listening to songs, for instance, you know that "loudness" and "lyric repetition" are both typical attributes for sections you have judged to be choruses. When you hear a new passage, you assess membership to the chorus category by comparing the attributes of this new passage to the attributes in your summary representation. Note that these two theories are similar: Do you compare a new passage to a set of abstracted features derived from previously-heard songs, or do you compare a new passage to the common features of a set of remembered passages? This question is moot, since neither theory fully accounts for all of the empirical evidence on conceptual categorization. Presumably, you use both methods, along with a number of other possible strategies, such as family resemblances, feature combinations, and schemata. ${ }^{(13)}$ Without a doubt, comprehensive theories of conceptual categorization are messy. ${ }^{(14)}$

[2.2] Because the field of cognitive psychology has shown that our understanding of concepts is impossible to fully explain (at least as yet), I will not try to exhaustively delineate how we understand section roles such as verse, chorus, or bridge. ${ }^{(15)}$ That said, I will provide one illustrative example here, Mariah Carey's Billboard \#1 hit song “I Don’t Wanna Cry” (1990), which I have chosen because it evinces relatively clear instances of section roles and the prototypical arrangement of these sections. The song can be heard in Example 3a, and my conception of the song's form is shown in Example 3b. In my form chart, I provide not only the local section labels (e.g., verse, prechorus, chorus) but also the higher-level grouping structure, which I hear as a largescale AABA pattern, or "compound AABA". (16) (The diagonal lines in the grouping structure represent the possibility of hearing the link material as belonging to the A or B groups; more on that below.) By using this song as a reference point, I do not mean to imply that it portrays the best template or the only template for form in pop/rock music. (It is not the prototypical song, it is simply a prototypical song.) When looking at the form chart in Example 3b, though, I hope the reader recognizes a highly standardized song structure, one that includes all (or at least most) of the conventional form labels commonly used to describe the sections of a verse-chorus song. The fact that this song has so many different section roles is an important factor in the perceptual clarity of its form. Because the verse and chorus sections in "I Don't Wanna Cry" are so clear and distinct, for example, we are encouraged to hear the intervening material as the prechorus. Section roles, in other words, mutually reinforce one another here. 
[2.3] A variety of factors make the verse and chorus roles in this song clear to my ears. For example, the chorus has a palpably thicker texture than the verse, the chorus lyrics return on future iterations whereas the lyrics of the verse do not, the chorus melody is in a high register whereas the verse melody is in a low register, and the phrase structure of the chorus seems more goal-oriented than the verse (in that the vocal phrases in the verse avoid ending or beginning on hypermetric downbeats). For reference, Example $3 \mathrm{c}$ transcribes the melody, lyrics, and chords of the song up until the second verse. ${ }^{(17)}$ In terms of harmony, both the verse and chorus are relatively stable. But the chorus emphasizes the major tonic (A major), whereas the verse emphasizes the relative minor-a common scheme for verse-chorus pairings (Doll 2011). Note as well that the chorus includes internal text repetition (which is a common feature of chorus sections), since the title of the song occurs not only at the beginning of the section but also at its end. I consider this repeated title text to be a refrain, even though some authors allow for a refrain to occur only at the end of a verse. ${ }^{(18)}$

[2.4] Verse and chorus sections in "I Don't Wanna Cry" are further differentiated by the existence of the intervening prechorus (mm. 15-18 in Example 3c), which interjects unstable harmonic material as it transitions between relative key areas. This prechorus displays transitional elements in various other domains as well. In terms of instrumentation, the sparse texture of the verse becomes more lively and thick, with a busier acoustic guitar part, a move into a higher register by the synthesized strings, and the addition of synthesized background vocals. A transitional quality can also be seen in the register of the prechorus melody, which shifts from the lower tessitura of the verse to the higher tessitura of the chorus. Admittedly, this prechorus may seem somewhat short, at only four bars in the meter I have chosen. In terms of absolute time, though, it lasts about as long - at roughly 15 seconds - as many prechorus sections that other theorists have identified, such as the 15-second prechorus in "Talking in Your Sleep" (The Romantics, 1984) that Summach (2011) uses as his primary example. From this perspective, therefore, the prechorus in "I Don't Wanna Cry" seems long enough to feel like a standalone section.

[2.5] Between the first chorus and the second verse ( $\mathrm{mm} .27-30$ in Example 3c) is a section I refer to as the link, although no standard term for this section role currently exists. The word "link" has received some currency in recent scholarly literature (Stephenson 2002, 134; Endrinal 2008, 68-69), which is why I use it here, but a variety of alternative labels can also be found, including "interlude," "turnaround," and "Janus module."(19) As is common in other songs, the link recycles the intro material, thereby restarting the verse-prechorus-chorus cycle. Note the dramatic drop in texture and the return to $\mathrm{F}^{\#}$ minor, for example. At the same time, however, the link acts as the end of the chorus, which is especially salient in this song since the title line in the vocal melody spills over into the link. Indeed, this spillover of the title line into the link is a relatively common feature for chorus-link boundaries. ${ }^{(20)}$ Mariah Carey's repetition of the title line in the middle of the link (around m. 29) creates a further connection between the link and the chorus. The link material, therefore, can be seen to both end the first large-scale A group and begin the second large-scale A group, as reflected by the diagonal line in the grouping column in my form chart above.

[2.6] I have transcribed the bridge material of the song in Example 3d. One factor supporting a hearing of this passage as the bridge is that it occurs exactly where we would expect a bridge, i.e., after the second iteration of the chorus and before the final iteration of the chorus. Another factor is that the bridge is harmonically unstable, as it spawns an expressive "pump-up" modulation from the original key of A major to the new key of $B^{b}$ major. ${ }^{(21)}$ The melody here is soaring, with the $F^{\#}$ in $\mathrm{m} .57$ and the $\mathrm{F}^{\natural}$ in $\mathrm{m} .59$ being the highest notes reached yet in the lead vocal. And the lyrics, all of which are new, seem to summarize the sentiment of the song in a way that is comparable to the role of the chorus itself. Viewing this passage as the bridge, it stands as the main component of the large-scale " $\mathrm{B}$ " group, providing contrast between the end of the second " $\mathrm{A}$ " group and the abbreviated final " $\mathrm{A}$ " group. I thus see two levels of "bridge" quality here: one at the section level 
(the vocal bridge itself) and another at the grouping level. ${ }^{(22)}$ The idea that "bridge-ness" can exist on different hierarchical levels of a song's form is a central factor in creating section ambiguity, as I show later in the paper.

[2.7] The material I have identified as the bridge could also be considered a variation on the prechorus. Indeed, the material in Example $3 \mathrm{~d}$ is built on the same harmonic progression as the prechorus (mm. 15-18 of Example 3c). It is fairly common, however, for two separate sections of a pop/rock song to share the same harmonic content, as exemplified by Covach's "simple versechorus" form (2005). Ultimately, I find it somewhat hard to say whether mm. 55-59 in "I Don't Wanna Cry" represent a bridge or a recomposed prechorus; since either section role might precede a final chorus, both analyses seem plausible. The fact that this song contains some ambiguity with regard to section roles may seem to compromise its function as an illustrative example. But in my experience, it is extremely difficult if not impossible to find a commercially successful song from this era that includes all of the typical section roles without any element of ambiguity. I might be able to offer a song with a clear verse and a clear chorus section, for example, but it would lack a clear prechorus. As I hope to convince the reader with the following examples, pop/rock songs consistently challenge our conceptual categorization schemes, if only because real music involves so many perceptual parameters.

\section{"Second Verse, Same as the First"}

[3.1] I turn now to the central concern of this essay: an examination of different types of ambiguity typically encountered in the form of a pop/rock song. I begin with those situations in which it is not clear whether a passage should be considered one long span of verse or a verse plus some other section, such as a verse followed by a chorus or a verse followed by a prechorus. This is the simplest and most common type of formal ambiguity in pop/rock music, and as such, may be the most familiar to the reader. Generally speaking, verse ambiguity arises from weak differentiation between the verse material itself and the material that follows.

[3.2] At the beginning of this essay, we saw an instance of weak verse-chorus differentiation in the song "One" by U2. The lack of clear verse-chorus separation in that case was due in large part to an absence of strong chorus attributes in the domain of lyrics. Yet even when the lyrics of a song more strongly convey chorus quality, verse-chorus separation may still be relatively weak due to a lack of differentiation in other domains. The song "When Doves Cry" (Prince \& the Revolution, 1984) provides a good example in this regard. In particular, the opening 32 bars of vocal material (Example 4) have been analyzed as one long span of verse material (Temperley 2013) and alternatively as a 16-bar verse followed by a 16-bar chorus (Summach 2012, 108-9). I have omitted chord symbols from my transcription, since the underlying harmonies are somewhat unclear; certainly, harmony plays no significant role in differentiating the first half of these 32 bars from the second half. Nor does the melody seem to participate in section differentiation, since neither the phrase structure nor the pitch content change significantly from the first half to the second half. The perception of a chorus section hinges primarily on two factors. The first is the very slight thickening of texture, achieved in the first iteration of this material through the addition of the synthesizer lead as well as a more consistent doubling of the lead vocal. That said, the change in texture is rather subtle; no distorted guitars or heavy drums come in. The second and perhaps strongest factor is the lyrics: the text from the second half of the opening 32-bar passage repeats almost exactly at later points in the song (both at 2:04 and 2:50), and some internal repetition ("Maybe I'm just. ...") occurs as well. Nonetheless, the internal repetition is mild and does not include the title of the song. Perhaps, then, the repetition of lyrics here is simply a case of "second verse, same as the first." (23)

[3.3] The identification of a chorus section within "When Doves Cry" thus can be seen as highly 
contingent on the analyst's perspective or frame of mind. If we are looking for a chorus in this song, we can find one. But if we are not necessarily looking for a chorus, we may not hear it. Again, we could strictly define the category of "chorus" to be, for example, those passages that repeat lyrics on future iterations; and by that rubric, "When Doves Cry" has a chorus while "One" does not. Yet to my ears, a standalone chorus is more salient in "One" than in "When Doves Cry," primarily because of the musical features that participate in my overall assessment of the passage. This is not to say, of course, that one song has a chorus and the other does not. Rather, the existence of a chorus depends on subjective weighting of a variety of musical and lyrical attributes, some of which may convey conflicting information.

[3.4] Perhaps the most commonly encountered type of ambiguity in pop/rock form involves the issue of whether a passage is a refrain or standalone chorus. This type of ambiguity is similar to the previous case, as it affects whether we hear the song as a one-part form (verse only) or a two-part form (verse-chorus). ${ }^{(24)}$ The song "I Still Haven't Found What I'm Looking For" (U2, 1987) provides an excellent example in this regard, since the opening 24-bar vocal passage of the song (Example 5) has been analyzed as a 16-bar verse followed by an 8-bar chorus (Scott 2003, 411; Temperley 2013) and also as a 24-bar verse in which the last eight bars constitute a refrain (Harris 2006, 210-12; Endrinal 2008, 147). Undeniably, the last eight bars of this 24-bar passage are the most chorus-like moment of the main material, but do they rise to the level of separating from the verse to stand as their own discrete section? On one hand, these eight bars seem long enough to warrant being considered a separate unit. But on the other hand, the last eight bars unmistakably act as the completion of a single harmonic and phrase arc that spans the larger 24-bar passage as a whole. Especially for those listeners familiar with the blues, the last eight bars sound very much like two iterations of the final cadential 4-bar phrase of a 12-bar blues. Here again, it appears that if listeners want to analyze the song as having a chorus, they can; if not, there is no overwhelming perceptual evidence to do so.

[3.5] Other cases of ambiguity involving verse sections arise from a weak differentiation of prechorus quality. In particular, if the chorus of a song is clear, it may be unclear whether the material preceding this chorus should be considered one cohesive span of verse or a verse section followed by a prechorus. The song "Smells Like Teen Spirit" (Nirvana, 1991) provides a good illustration of this situation, since some theorists have analyzed it as including verse, prechorus, and chorus sections (Doll 2011 [15]; Adams 2015, 9) while others have partitioned it as verse and chorus sections only with no prechorus (Covach 2009, 512; Temperley 2013). At issue is whether the eight bars prior to the chorus should be considered a standalone prechorus or simply more verse material (Example 6a). Unlike clearer examples of prechorus sections, we find no change of harmony prior to the chorus. Harmonic instability and harmonic contrast may be such strong factors in our perception of a prechorus that their absence significantly mutes our perception of a separate prechorus section. Undoubtedly, a change in the bass line during the eight bars prior to the chorus, as can be heard in my recomposition in Example 6b, would more strongly convey the sense of a discrete prechorus. But the lack of such a change does not nullify the transitional, prechorus-like elements heard in other domains. In terms of texture, for example, the sparse instrumentation of the first eight bars of the verse becomes thicker in the next eight bars as the hihat opens up (and thus becomes louder and resonates longer), the vocals become doubled, and the electric guitar becomes more distorted and active, all elements that presage the dramatic textural change in the chorus. The lyrics also depart from our expectations of verse material, in that they become more internally repetitive and repeat on future iterations.

[3.6] As "Smells Like Teen Spirit" and similar examples show, prechorus quality can be considered to exist along a continuum. Many songs might or might not be considered to have a prechorus, depending on the strength of prechorus attributes and the disposition of the analyst. In some cases, it may not be clear where a prechorus label would even begin, as when prechorus-like attributes 
have staggered entrances. An example of this scenario can be found in the song "Run to You" (Bryan Adams, 1984). The opening vocal passage of this song (Example 7a) begins with eight bars of clear verse material and, after eight more bars, we hear a clear chorus section. But what of the eight bars prior to this chorus? Is there a prechorus during this span of music, and if so, where?

[3.7] In the ninth bar after the verse begins ("Oh, but her love is cold"), the melodic phrase rhythm fragments into smaller spans. As a result, the rhyme scheme in the lyrics becomes more compressed, going from a rhyme every four bars to a rhyme every two bars. This increased pace can be viewed as a transition towards the 2-bar repetitions of the title text in the chorus itself. Moreover, the melodic content beginning in $\mathrm{m} .17$ emphasizes the high $\mathrm{A}^{b}$, which foreshadows the high, metrically accented $A^{b}$ in the first half of the chorus. Yet although some transitional aspects can be observed in the third 4-bar hypermeasure, the guitars and bass continue to repeat the same harmonic content found earlier (albeit only the latter half of the main riff). In the fourth 4-bar hypermeasure ("When it gets too much"), however, we hear a significant harmonic move away from this repeating chord pattern, with the bVI-bVII motion strongly preparing the arrival of the minor tonic at the beginning of the chorus. ${ }^{(25)}$ Additionally, the texture noticeably thickens, as the drums shift from a side-stick pattern to a standard kick-snare pattern. The bass guitar also intensifies the feeling of forward drive through its straight eighth-note part. As a final factor, note that while most of the lyrics prior to the chorus do not repeat on the second iteration of this passage, the line "I need to feel your touch" does repeat when this material returns later in the song. Overall, we are thus presented with a gradual and continual buildup of prechorus-like qualities during the eight bars prior to the chorus.

[3.8] "Run to You" thus presents a somewhat different type of ambiguity than the previous examples. Instead of having weak differentiation between the verse and a following section, we see the strength of prechorus quality continuously increasing as the chorus approaches. It is as if the prototypical large-scale verse-prechorus-chorus unit, as for example in "I Don't Wanna Cry," has been compressed or "telescoped" into a shorter span of absolute time, as shown in Example 7b. ${ }^{(26)}$ The result is a changing blend of verse and prechorus features as the chorus is approached. I borrow the term "blend" from the field of linguistics to refer to those situations in which aspects of two (or more) section roles appear to exist within the same passage (Denham and Lobeck 2009, 197). Just as the term "brunch" is a blend of the seemingly mutually exclusive categories of "breakfast" and "lunch," for instance, some passages in pop/rock music may be seen to blend characteristics of two seemingly mutually exclusive section roles.

\section{"Don't Bore Us, Get to the Chorus"}

[4.1] The notion that different sections may telescope or collapse into one another, and in so doing create blends of otherwise distinct section roles, is particularly applicable as we consider various instances of chorus ambiguity aside from the verse-chorus ambiguity discussed above. In many songs, although we may feel strongly that a chorus exists, some latent ambiguity may underlie our categorization process. This occurs most often when a chorus role blends with one of its two neighboring roles, the prechorus or link.

[4.2] A good example with which to begin this discussion is the song "Hip to Be Square" (Huey Lewis and the News, 1986). As can be heard in Example 8a, the song begins with an eight-bar introduction, which consists of a two-bar guitar riff that is played four times. Following the introduction, we hear what is clearly verse material in $\mathrm{mm}$. 9-16. This verse material is based on the same chord progression as the introduction, although the main riff is significantly understated. Following this verse material, we hear in mm. 17-24 what sounds very much like the prechorus of the song, in significant part due to the unstable nature of the harmonic content, which moves from the subdominant at its beginning to a "soul dominant" (A/B) at the end.(27) What should we make, 
though, of the following four-bar passage, from mm. 25-29?

[4.3] Nobile argues that mm. 25-29 in "Hip to Be Square" are the chorus of the song, mostly due to the relatively clear prechorus material that precedes these measures $(2014,170-71)$. Indeed, m. 25 seems like an arrival point due to the unstable harmonic material that leads into it. Moreover, $\mathrm{mm}$. 25-29 contain two instances of the title lyric, making these four bars seem like a focal point. That said, these four bars also convey an unmistakable link quality. Most notably, the guitar riff of the intro returns, just as would normally happen in a link section, which typically heralds a restart of the large-scale grouping structure. The brevity of the passage is also much more characteristic of a link than a chorus. The bleeding over of the title lyric and further repetition of this title is not uncommon with link material either, as seen in "I Don't Wanna Cry," discussed above.

[4.4] Given this analysis, I posit that it may be preferable to consider these four bars as a blend of chorus and link section roles. Note that the verse returns immediately in $\mathrm{m}$. 30, such that were we to consider mm. 25-29 to be the chorus, the song would contain no distinct link section. This is because, arguably, the chorus and link roles have merged into a single passage. Here again, we can consider the resultant blend to be a telescoping of song form, facilitated by the adjacency of chorus and link roles in their more prototypical instantiations.

[4.5] It is worth noting that in the second appearance of the main material in "Hip to Be Square," the chorus/link blend is extended from four bars to eight, as can be heard in Example 8b. This doubled length, which is accomplished by essentially repeating the original four bars of chorus/link material, undeniably adds greater structural weight to this passage within the largescale form. As a result, we could say it becomes somewhat more chorus-like in its second iteration. Nonetheless, the extended length is not enough to negate the feeling that the section combines aspects of both chorus and link roles within a single musical span.

[4.6] Instances of chorus/link blends can be found in many other songs from the era, in various degrees of combination. Another excellent example occurs in the song "Jump" (Van Halen, 1984). Like "Hip to Be Square," "Jump" begins with a well-defined riff in the introduction, played here on synthesizer, as can be heard in Example 9a. The vocal material that follows strongly warrants being partitioned into three distinct sections. The first section, $\mathrm{mm}$. 17-32, seems to clearly act as verse material; the second section, $\mathrm{mm}$. 33-41, is a nine-bar span of less harmonically stable material; and in the third section, mm. 42-49, we hear a return of the introductory riff along with fragmented repetitions of the title text. Summach analyzes these three vocal sections as verse, prechorus, and chorus, respectively $(2012,316)$, which is probably the way that most listeners would interpret these sections given existing approaches to form in pop/rock music. But there is something about $\mathrm{mm} .42-49$ that make them feel as if the chorus quality is somewhat mitigated. One aspect is the relative sparseness of the main vocal. Another is the completely static nature of its harmonic content. Especially in contrast to the strong feeling of motion and momentum in $\mathrm{mm}$. 33-41, $\mathrm{mm}$. 42-49 seem somewhat flat and unexciting, at least from a harmonic perspective. In addition, there is no thickening of texture as we might expect in a chorus; instead, the accompaniment thins out in a return to the opening texture. Overall, mm. 42-49 seem like an afterthought rather than a climactic point, as if the main thrust of the song has already passed. This afterthought quality may also relate to the organization of the vocal melody, which is so strongly end-accented-as would be characteristic of vocal material in a prototypical link - that it conveys a substantial sense of closure. For these reasons, I perceive "Jump" as another instance in which link and chorus roles combine into a single passage. As in "Hip to Be Square," this chorus/link blend moves immediately back to the verse, without any intervening material, since link and chorus roles have merged.

[4.7] Before moving on, I want to point out one more interesting feature of "Jump." The second iteration of the main vocal material (as can be heard in Example 9b) has the same lyrics in the 
second section (". . .can't you see me standing here. ..") as it does in its first iteration. I have presumed this harmonically unstable passage to be the prechorus, but it has at least one element of chorus-like quality due to this text repetition. The fact that this second section has the thickest texture of the three main sections further reinforces this feeling of chorus quality. We could thus consider the main material in Example 9a to be a verse-chorus-link form, with mm. 33-41 acting as the chorus and mm. $42-49$ acting as the link. Some readers may balk at accepting this analysis, as chorus quality may seem stronger in $\mathrm{mm}$. 42-49 than in $\mathrm{mm}$. 33-41. But it will be useful to keep this additional layer of ambiguity in mind as we consider the following two examples.

[4.8] Along these lines, listen to the main vocal material in "The Power of Love" (Huey Lewis and the News, 1985), given in Example 10, and consider how section roles might be assigned. There are obviously three distinct sections: an 8-bar C-minor passage in $\mathrm{mm}$. 21-28 that clearly acts as verse material, a 9-bar C-major passage in $\mathrm{mm}$. 29-37, and a shorter 4-bar passage back in C minor in $\mathrm{mm}$. 38-41, after which the song returns to another verse (not shown in my transcription). Notice how similar this song is in construction to the other Huey Lewis and the News song discussed above, "Hip to Be Square" (Examples 8a and 8b). Both have an 8-bar verse, followed by transitional material that leads up to a strong dominant chord, which prepares the title overlap into a 4-bar passage that includes the return of the main riff along with a repeat of the title text two bars later. For these reasons, we might hear "The Power of Love" as evincing a verse section, followed by a 9-bar prechorus, which then leads to a chorus/link blend. Summach $(2012,318)$, however, labels mm. 29-37 in "The Power of Love" as the chorus, and there are good reasons to do so. The lyrics of this middle passage, for example, repeat at each appearance of the section; the lead vocal has a generally higher register than the sections before and after it; and the texture is also thicker than the surrounding sections, with the hi-hat opening up and a distorted guitar doubling the bass.

[4.9] Overall, I agree with Summach that there is a chorus-like quality to mm. 29-37 in "The Power of Love." At the same time, I cannot help but hear this song in relationship to other songsincluding "Jump," "Hip to Be Square," and those with more clear section roles-such that mm. 29-37 have an appreciable prechorus quality as well. Harmony perhaps contributes in large part to that feeling. Although one could say that mm. 29-37 in "The Power of Love" begin a tonic sonority (C major) and are thus somewhat more stable than a typical prechorus, the recurring C-major chord does not have the same strength of tonic quality, at least to my ears, as does the C-minor chord that begins the verse and reappears in $\mathrm{m}$. 38. It is hard to fully explain why, although the rising bass line, which quickly puts the $\mathrm{C}$-major chord in first inversion, may be a significant factor. Given a verse tonic of $\mathrm{C}$ minor, the $\mathrm{C}$ major chord may be acting more as V/IV than a modally altered tonic. As a result, I hear this passage as a prechorus/chorus blend, which can be understood as resulting from a telescoping of song form that merges the prechorus and chorus roles into a single passage.

[4.10] Even though the previous three examples share similar organization schemes, it seems that some iterations of that scheme are more amenable to hearing a prechorus/chorus blend (i.e., "The Power of Love") while others are more amenable to hearing a chorus/link blend (i.e., "Jump"). In some situations, the choice of which blend might be more appropriate is itself ambiguous. I find this to be the case with "Summer of "69" (Bryan Adams, 1984). The opening of the song (Example 11a) presents the listener with two discrete vocal sections. The first, in mm. 3-18, clearly acts as verse material. The second, in mm. 19-28, is open to interpretation however. In m. 29, the end of the second section overlaps into what seems to be four bars of link material, since there are no vocals from $\mathrm{m}$. 29 until the entrance of the second verse. On this basis, we may judge mm. 19-28 to be the chorus of the song, since there is no vocal material that follows it. Indeed, the end of this second section contains a catchy refrain ("Those were the best days of my life"), which is highlighted by the stop-time texture. At the same time, the harmonic material in this second section has a searching quality, which may feel somewhat prechorus-like. We might as a result posit a 
prechorus/chorus blend here, if perhaps tilted towards the chorus role.

[4.11] The second iteration of the main vocal material (Example 11b) challenges this hearing, however. The second section, $\mathrm{mm}$. 41-50, does not repeat the lyrics from its first iteration: besides the isolated word "forever" at the end of the first phrase, only the end refrain, "Those were the best days of my life," returns. As an additional complication, what had been the link material now spans eight bars of music with vocals that include the title of the song (mm. 51-58). Perhaps mm. 41-50 are thus the prechorus of the song, and $\mathrm{mm}$. 51-58 are a chorus/link blend. It is undeniable that the stop-time refrain ( $\mathrm{mm} .49-50)$ is a high point in the song, but does this vocal phrase end the chorus or begin the chorus? The final iteration of main vocal material (Example 11c) clouds the question further, in that the lyrics in $\mathrm{mm} .41-50$ are repeated mostly verbatim. Overall, there is a strong feeling of a chorus in this song, but it is as if there are two types of choruses, one a prechorus/chorus blend, the other a chorus/link blend. Interpreting the telescoping of form in this song, therefore, it might be best to say that the chorus role has been dispersed over both neighboring section roles.

\section{"Where's That Confounded Bridge?"}

[5.1] The final type of ambiguity common in pop/rock songs from this era involves the bridge role. In some songs, this ambiguity arises because the bridge role is only weakly expressed; in other songs, there may be a blend of section roles, or some combination of these two situations. One important factor in this regard is our association of the bridge role with a particular location in the song form, namely, before the last iteration of the large-scale A group, which is often just a final chorus. Related to this factor is the different hierarchical implications of the bridge role, whether at the level of verse and chorus or at the level of the large-scale AABA grouping.

[5.2] As seen in "I Don't Wanna Cry," the potential for ambiguity between bridge and prechorus roles is facilitated in large part by two central attributes these roles share: both typically have unstable harmonic content, beginning off-tonic and ending on a dominant-functioning sonority; and both typically precede a chorus. Since "I Don't Wanna Cry" showed an ambiguity between prechorus and bridge that leaned more toward the bridge role, it is worth looking at a case that leans more toward the prechorus role. The song "Papa Don't Preach" (Madonna, 1986) provides a good example in this regard. The initial prechorus (Example 12a) and the vocal material prior to the final choruses (Example 12b) match closely in melody, harmony, and instrumentation, with only small differences in the first six bars due to text setting. Given the choice between prechorus and bridge labels, therefore, it would seem more reasonable to refer to the vocal passage in Example $12 \mathrm{~b}$ as another iteration of prechorus material. But the end of this final prechorus is significantly different than prior prechorus iterations, most notably in the avoidance of the F-minor tonic in the seventh bar, followed by a two-bar phrase extension on the strongest and clearest dominant sonority of the entire song. This reharmonization and phrase extension relate to the blending of some bridge quality into the prechorus material.

[5.3] If a song lacks a clear and distinct bridge section, the bridge role (or bridge attributes) may be blended with another section, such that a large-scale AABA grouping pattern may still be perceived. For example, Stephenson analyzes the song "Wrapped Around Your Finger" (The Police, 1983) as a verse-chorus strophic form, i.e., a song that simply repeats blocks of verse and chorus material without any intervening bridge $(2002,140)$. In his analysis, the song contains three blocks of verse-chorus material, the first starting around 0:30 in the original recording, the second around 2:05, and the third around 3:09, thus creating a large-scale AAA grouping pattern. For reference, Example 13a transcribes the first 16 bars of verse material in the song. Indeed, what Stephenson views as the third iteration of verse material (Example 13b) does present rather similar melodic content and phrase structure to prior iterations of verse material. But the music in Example 
$13 \mathrm{~b}$ includes a number of significant differences from earlier verse sections. One obvious change involves the harmonic content: instead of the static toggling between A-minor and E-minor chords, a new bass line imparts a heightened sense of harmonic directionality. This bass line more strongly groups these measures in 8-bar units, since the minor tonic chord now appears only twice in the 16-bar passage. The melody also undergoes a subtle but important change. The strong sense of closure found at the end of every other vocal phrase in earlier verse sections is now absent. As a result, the feeling of instability and forward motion is further increased. The instrumentation also conveys a sense of drive, in that halfway through the 16 bars before the final chorus, the drums switch to the first standard rock beat of the entire song, while the electric guitar increases the tension with eighth-note repetitions of the pitch A. Furthermore, these features appear after two essentially identical iterations of verse and chorus material, at the exact moment where we would expect a bridge in the form of the song. Overall, therefore, the material in Example $13 \mathrm{~b}$ conveys a strong sense of bridge functionality if only blended into to the third iteration of verse material.

[5.4] As these last two examples highlight, our local section-label choices can influence how we view the large-scale organization of a song. If you understand the music in Example $13 \mathrm{~b}$ as a varied instance of verse material, for example, you would say that "Wrapped Around Your Finger" is in a strophic form; if you interpret this same music as a bridge, however, you would say the song is in a compound AABA form. Thus, ambiguity with regard to form may exist not only on the local section level but also on the large-scale grouping level of a song. Some songs, therefore, may exhibit two (or more) overlapping grouping layers.

[5.5] Blends of a bridge role with another section role can occur in a variety of situations and to differing degrees. The work by Endrinal $(2008,2011)$ on the music of U2 is particularly relevant in this regard, as he deprecates the term "bridge" in favor of the term "interverse." Endrinal feels that U2's music includes many passages at the position in a song where we might expect a typical bridge, yet these passages often do not fully convey a clear bridge role. To Endrinal, the term "interverse" is a more neutral label, and he goes on to categorize types of interverses based on two parameters: whether these sections are tonally open ("continuous") or closed ("sectional"), and whether they consist mostly of new material ("independent") or recycle material from a previous section ("dependent"). Alternatively, these interverse subcategories can be conceptualized as different levels of bridge strength and role blending. For instance, an independent continuous interverse-new musical material that lacks tonal closure-would be a passage that presents relatively clear bridge quality, whereas an independent sectional interverse-new music material that is tonally closed - would be a passage in which bridge quality is comparatively weaker. A dependent interverse, whether continuous or sectional, would be a passage in which the bridge role is blended with some other section role.

[5.6] As it turns out, the variety of ways that bridge blends can occur challenges any strict categorization scheme. Consider, for example, the song "Mysterious Ways" (U2, 1991). Endrinal's interpretation of the song's form as an overall compound AABA pattern is shown in Example 14a (a reproduction of Example 5 from his 2011 article). The independent continuous interverse, abbreviated " $\mathrm{N}$ " with an " $\mathrm{i}$ " superscript and " $\mathrm{c}$ " subscript, occurs exactly where we would expect a bridge: after two iterations of the larger "VTC" group (i.e., a verse-prechorus-chorus block) and immediately prior to the last chorus. Before I discuss this interverse, it will be useful for the reader to be familiar with the chorus material-especially the bass line, which plays an ostinato pattern centered on tonic despite the chord changes in the upper parts - as can be heard in Example 14b. The interverse, which can be heard in Example 14c, begins with new material and thus, at least initially, warrants categorization as an independent section. Many listeners may accordingly hear the beginning of what sounds like a bridge section at this point in the song. But a critical change occurs halfway into this interverse, where the tonally static bass line from the chorus re-enters four bars prior to what Endrinal identifies as the final chorus. Accordingly, this interverse is neither 
independent nor dependent, in that it both presents new material and recycles old material. Instead, it is a partial blend of bridge and chorus.

[5.7] In these last three examples, we have seen the bridge role blend with material that had previously acted in verse, prechorus, and chorus roles. As this demonstrates, bridge quality may combine with a variety of different section types, in large part because our perception of a bridge is associated with generic principles of contrast at a particular location in the song form. A consequent effect is that "bridge-ness" may seem to be stretched (or distributed) across a number of what may otherwise appear to be independent sections, whether or not the song includes a clear instance of a standalone bridge section. The song "Take Me Home Tonight" (Eddie Money, 1986) provides an excellent example of this situation. Example 15a transcribes the beginning of the first verse (mm. 13-16), the first chorus (mm. 35-42), and the following link material (mm. 43-46), all of which express clear instances of these section roles. (The remaining verse and prechorus material are not directly relevant to my larger argument, so they have been omitted.)

[5.8] Of particular interest here is the material between the end of the second chorus (after m. 68) and the beginning of the final chorus (in m. 87), as provided in Example 15b. The intervening measures (mm. 69-86) encompass a number of separate sections. That said, a great deal of ambiguity and instability is palpable throughout this larger passage, which lends a general feeling that bridge quality spans across more than just a single section. The best candidate for a standalone bridge section is mm. 71-78, which elide the end of the second link. In m. 71, we hear a dramatic change in texture, accomplished in large part by the half-time feel in the drums and the introduction of the solo saxophone, neither of which have been heard in the song until this moment. The harmonic rhythm also slows down, stalling on the submediant, $\mathrm{B}^{b}$ minor. As the harmonies begin to gain momentum in $\mathrm{m}$. 75 , the lead vocal reappears. But the melodic and lyric content is drawn primarily from the end of the chorus, and so there seems to be a bridge/chorus blend at this point. Link material returns during mm. 79-82, although the textural changes introduced in $\mathrm{m} .71$ persist, at least somewhat. The bottom has now dropped out with the removal of the bass and guitar. Additionally, the drums - although no longer playing a half-time patternhave not fully returned to the standard beat heard throughout the rest of the song; instead, the drums pay homage to the well known beat from "Be My Baby" (The Ronettes, 1963) via omission of the snare on beat 2. This drum pattern continues through the verse-like material in mm. 83-86. But while the verse seems to return in $\mathrm{m} .83$, it is something of a mirage. Features of mm. 83-86 harken back to the material in $\mathrm{m} .71$, including the reappearance of the saxophone as well as the persistent emphasis on $\mathrm{B}^{b}$ by the bass guitar. So while chorus, link, and verse material are all encountered in mm. 71-86, a variety of factors preclude any clear or stable instantiation of these section roles. Instead, there is a persistent bridge quality that seems to underlie and thwart any attempt at stability prior to the re-entrance of the chorus in $\mathrm{m}$. 87 . We might even feel that bridge quality extends further on some level, in that the triumphant return of the chorus in $\mathrm{m} .87$ is significantly undercut by the lack of drums and bass, which do not enter until the second phrase in m. 91. A full repetition of the chorus (m. 95) is almost demanded in that it is not until this point that we hear the chorus return in its full glory.

\section{Conclusion}

[6.1] A pop/rock song, like any musical work, conveys its structure via numerous different domains: harmony, melody, rhythm, meter, dynamics, instrumentation, register, narrative, etc. The analysis of musical form is thus inherently complex because it encompasses all of these domains, which may or may not convey congruent formal analyses. In the approach to form in pop/rock music I present here, I posit that it is often counterproductive to think of section roles as mutually exclusive labels. Indeed, the most appropriate way to represent many moments in pop/rock music often seems to be via a blend of section roles. To date, though, it is extremely uncommon for an 
analysis to provide imbricated or coincident section labels. Understandably, we want to represent the form of a song in the clearest possible manner. In doing so, however, we run the risk of downplaying what are often the most intriguing aspects of a song.

[6.2] Ambiguity in song form arises in part from the fact that some section roles share similar prototypical attributes. For example, prechorus and bridge sections both typically involve unstable harmonic content that lacks tonal closure. One theory of conceptual categorization holds that we tend to create and organize categories such that they are maximally discriminable from one another (Rosch and Mervis 1975, 575-76). Indeed, the section-role labels we use may represent our best attempt to partition passages of pop/rock music into categories that contrast with one another in the greatest possible way. But the complexity of both real music and our perceptual processes thwarts any strict walling-off of these section roles as entirely contrasting units of musical form.

[6.3] On a practical level, some readers may feel that the approach to ambiguity I have described above is unwieldy, in that simply calling a section "the chorus" may seem to be problematic in and of itself. I have, after all, offered alternative viewpoints to many extant analyses. In doing so, I do not mean to criticize these analyses; I think each analyst cited in this essay is responding to salient factors of form heard in the music. Instead, I argue for a multivalent approach to form in pop/rock music that encourages us to view the form of any given song as a response to shared conceptions of song form. ${ }^{(28)}$ In other words, instead of asking, "Does this song have a bridge?," we may be better served by asking, "How is the bridge role manifested in this song?"(29)

[6.4] On a related note, some readers may feel the analytical approach I have outlined here does not reflect the personal, subjective, and contextual interpretation of section labels. Since everyone interacts with and listens to a different body of music during their lifetime, one could argue that we have each developed highly personalized notions of what constitutes more or less representative examples of section labels. Consequently, no single shared understanding of prototypical situations can be said to exist. Someone who is an avid Michael Jackson fan, for example, may have an entirely different understanding of what constitutes a typical verse than someone who listens primarily to heavy metal. In this regard, it is worth pointing out that research in cognitive psychology shows that subjects overwhelmingly agree on judgments of those more central and clear members of a category, even if they disagree on the exact boundaries and details of those categories (Rosch 1978). Nevertheless, different eras and styles of rock music undoubtedly utilize different strategies for organizing musical material. It is for this reason that I limited my examples to pop/rock music from 1982-1991, although even within this time frame, specific traits may associate with a particular section role more strongly in the music of one artist than in the music of another. For this reason, style analysis has been and will continue to be a valuable and worthwhile endeavor. In conclusion, this essay is meant not to act as a definitive guide to form in pop/rock music, even given the restrictions of the era under consideration. Rather, it is meant to exemplify a mindset that helps us better appreciate how songs continue to fascinate and enchant us given the confines of a highly limited palette of form and section types.

Trevor de Clercq

Middle Tennessee State University

Department of Recording Industry

1301 East Main Street, Box 21

Murfreesboro, TN 37132

trevor.declercq@gmail.com

Works Cited 
Adams, Kyle. 2015. “What Did Danger Mouse Do? The Grey Album and Musical Composition in Configurable Culture." Music Theory Spectrum 37 (1): 7-24.

Agmon, Eytan. 1995. “Functional Harmony Revisited: A Prototype-Theoretic Approach.” Music Theory Spectrum 17 (2): 196-214.

Biamonte, Nicole. 2010. “Triadic Modal and Pentatonic Patterns in Rock Music.” Music Theory Spectrum 32 (2): 95-110.

Bruderer, Michael, Martin McKinney, and Armin Kohlrausch. 2006. "Structural Boundary Perception in Popular Music." In Proceedings of the 7th International Conference on Music Information Retrieval (ISMIR), edited by Kjell Lemström, Adam Tindale, and Roger Dannenberg, 198-201. University of Victoria.

Burgoyne, John Ashley. 2011. “Stochastic Processes and Database-Driven Musicology.” PhD diss., McGill University.

Burnham, Scott. 2002. "Form." In The Cambridge History of Western Music Theory, ed. Thomas Christensen, 880-906. Cambridge University Press.

Caplin, William. 1998. Classical Form: A Theory of Formal Functions for the Instrumental Music of Haydn, Mozart, and Beethoven. Oxford University Press.

Covach, John. 2005. "Form in Rock Music: A Primer." In Engaging Music: Essays in Music Analysis, ed. Deborah Stein, 65-76. Oxford University Press.

- 2006. "From 'Craft' to 'Art': Formal Structure in the Music of the Beatles." In Reading the Beatles: Cultural Studies, Literary Criticism, and the Fab Four, ed. Kenneth Womack and Todd Davis, 37-53. SUNY Albany Press.

2009. What's That Sound? An Introduction to Rock and Its History, 2nd ed. W. W. Norton.

de Clercq, Trevor. 2012. "Sections and Successions in Successful Songs: A Prototype Approach to Form in Rock Music." PhD diss., Eastman School of Music.

. 2016. "Measuring a Measure: Absolute Time as a Factor for Determining Bar Lengths and Meter in Pop/Rock Music." Music Theory Online 22.3. http://mtosmt.org/issues/mto.16.22.3 /mto.16.22.3.declercq.html

_ 2017. “Interactions Between Harmony and Form in a Corpus of Rock Music." Journal of Music Theory 61 (2): 143-70 .

Denham, Kristin and Anne Lobeck. 2009. Linguistics for Everyone: An Introduction. Wadsworth.

Doll, Christopher. 2009. “Transformation in Rock Harmony: An Explanatory Strategy.” GAMUT 2 (1): 1-44. http://trace.tennessee.edu/cgi/viewcontent.cgi?article=1000\&context=gamut

_ 2011. "Rockin' Out: Expressive Modulation in Verse-Chorus Form." Music Theory Online 17.3. http://www.mtosmt.org/issues/mto.11.17.3/mto.11.17.3.doll.html

Endrinal, Christopher. 2008. "Form and Style in the Music of U2." PhD diss., Florida State University. 2011. “Burning Bridges: Defining the Interverse in the Music of U2." Music Theory Online 17.3. http://www.mtosmt.org/issues/mto.11.17.3/mto.11.17.3.endrinal.html

Everett, Walter. 2009. The Foundations of Rock: From "Blue Suede Shoes" to "Suite: Judy Blue Eyes." 
Oxford University Press.

Gjerdingen, Robert. 2007. Music in the Galant Style. Oxford University Press.

Hall, Rich. 1984. Sniglets: Any Word That Doesn't Appear in the Dictionary, but Should. Macmillan.

Harris, K. Paul. 2006. “U2's Creative Process: Sketching in Sound.” PhD diss., University of North Carolina, Chapel Hill.

Lakoff, George. 1987. Women, Fire, and Dangerous Things: What Categories Reveal about the Mind. University of Chicago Press.

Lakoff, George, and Mark Johnson. 1980. Metaphors We Live By. University of Chicago Press.

Moore, Allan. 2001. Rock: The Primary Text: Developing a Musicology of Rock, 2nd ed. Ashgate.

Murphy, Gregory. 2002. The Big Book of Concepts. MIT Press.

Neal, Jocelyn. 2007. "Narrative Paradigms, Musical Signifiers, and Form as Function in Country Music." Music Theory Spectrum 29 (1): 41-72.

Nobile, Drew. 2014. "A Structural Approach to the Analysis of Rock Music." PhD diss., City University of New York.

. 2016. "Harmonic Function in Rock Music: A Syntactical Approach." Journal of Music Theory 60 (2): 149-80.

Osborn, Brad. 2010. “Beyond Verse and Chorus: Experimental Formal Structures in Post-Millennial Rock Music." PhD diss., University of Washington.

_ 2013. "Subverting the Verse-Chorus Paradigm: Terminally Climactic Forms in Recent Rock Music." Music Theory Spectrum 35 (1): 23-47.

Riley, Jim. 2010. Song Charting Made Easy: A Play-Along Guide to the Nashville Number System. Hal Leonard.

Rosch, Eleanor. 1973. “Natural Categories." Cognitive Psychology 4: 328-50.

_ 1978. "Principles of Categorization." In Cognition and Categorization, ed. Eleanor Rosch and Barbara Lloyd, 27-48. Lawrence Erlbaum Associates.

Rosch, Eleanor and Carolyn Mervis. 1975. "Family Resemblances: Studies in the Internal Structure of Categories." Cognitive Psychology 7: 573-605.

Scott, Richard. 2003. Chord Progressions for Songwriters. iUniverse.

Smith, Edward and Douglas Medin. 1981. Categories and Concepts. Harvard University Press.

Smith, Jordan. 2014. "Explaining Listener Differences in the Perception of Musical Structure." PhD diss., University of London.

Spicer, Mark. 2017. "Fragile, Emergent, and Absent Tonics in Pop and Rock Songs." Music Theory Online 23.2. http://mtosmt.org/issues/mto.17.23.2/mto.17.23.2.spicer.html

Stephan-Robinson, Anna. 2009. “Form in Paul Simon's Music." PhD diss., Eastman School of Music.

Stephenson, Ken. 2002. What to Listen for in Rock: A Stylistic Analysis. Yale University Press. 
Summach, Jay. 2011. "The Structure, Function, and Genesis of the Prechorus." Music Theory Online 17.3. http://www.mtosmt.org/issues/mto.11.17.3/mto.11.17.3.summach.html

—_ 2012. “Form in Top-20 Rock Music, 1955-89.” PhD diss., Yale University.

Temperley, David. 2013. "A Corpus Study of Rock Music" (online analyses of 200 rock songs). http://rockcorpus.midside.com/harmonic_analyses/rs200_harmony/

von Appen, Ralf and Markus Frei-Hauenschild. 2015. "AABA, Refrain, Chorus, Bridge, Prechorus: Song Forms and Their Historical Development." Samples: Online Publication of the German Society for Popular Music Studies 13: 1-83.

Webster, James. 2009. "Formenlehre in Theory and Practice." In Musical Form, Forms, and Formenlehre: Three Methodological Reflections, edited by Pieter Bergé, 123-39. Leuven University Press.

Zbikowski, Lawrence. 2002. Conceptualizing Music: Cognitive Structure, Theory, and Analysis. Oxford University Press.

\section{Footnotes}

1. I have done my best to recreate the form chart from Endrinal 2008 based on his succession pattern (no timing information was provided). Harris 2006 shows an incorrect number of measures for the Coda section, probably because the free-form nature of these final bars makes it difficult to keep track of the form.

Return to text

2. Both authors concede that the form of this song is somewhat unconventional. For example, see Endrinal's discussion of the song's form in his explanation of chorus sections $(2008,69)$ as well as Harris's dedicated discussion of the song $(2006,96-100)$, in which he states that "this is another ambiguous form" (97).

Return to text

3. The relative-key pairing of verse and chorus sections is discussed in Doll (2011). The use of more dramatic melodic shapes in chorus sections is discussed in Everett $(2009,145)$.

Return to text

4. See, for instance, the overview of approaches to form in Burnham 2002, which spans theories of phrase and rhetoric (Mattheson and Koch), theme and development (Reicha and Marx), formal functions (Riemann and Caplin), and the "Will of the Tones" (Kurth and Schenker).

Return to text

5. Specifically, Smith found that, for the 492 recordings with two analyses, the median $f$-measure of inter-annotator agreement, allowing for a 3-second window of error, was 0.769 (2014, 74). An $f$-measure varies from 0 to 1 , with 1 being complete agreement. Note that the 3 -second window of error means that two boundaries could possibly be one or two measures out of alignment, depending on tempo, and still be considered to agree.

Return to text

6. In general, I take ambiguity to be a property of a thing (such as a section or section label), whereas I take subjectivity to reside in the personal interpretation of that thing. Thus, for example, an ambiguous form can lead to a high degree of subjectivity in its analysis.

Return to text

7. For a longer discussion of the problems with a definition-based approach, even with artificial 
categories such as the rules of a baseball game or the definition of a metal, see Murphy (2002, 16-24). I also refer the reader to Lakoff's seminal 1987 book on categories and the mind.

Return to text

8. My dissertation (de Clercq 2012) is an earlier attempt to tackle the issue of ambiguity in the analysis of form in pop/rock music; the current article builds on that work.

Return to text

9. Stephenson writes that "the point of formal analysis (i.e., morphological analysis) is not to identify passages with the proper labels, for the labels serve merely as points of reference around which to organize our thoughts" $(2002,133)$.

Return to text

10. See Figure 2 in von Appen and Frei-Hauenschild $(2015,73)$. Also, Summach $(2012,230)$ shows that by 1985 , arguably $90 \%$ of song structures in the Billboard Top 20 were in a verse-chorus format. Return to text

11. My argument here for an end date of 1991 parallels that used by Burgoyne $(2011,131)$ and Summach $(2012,13-14)$, both of whom choose an end date of 1991 and provide further justification for this particular cut-off.

Return to text

12. For some examples of other music-theoretic work that uses prototypes and exemplars, see Agmon 1995, Zbikowski 2002, and Gjerdingen 2007.

Return to text

13. My overview in this paragraph draws heavily on Chapter 3 in Murphy (2002). I highly recommend this resource as a starting point for any reader interested in learning more about theories of conceptual categorization.

Return to text

14. My use of the term "messy" comes from Murphy $(2002,492)$, who uses it in his conceit of the difficulty in creating a comprehensive theory of conceptual categorization.

Return to text

15. For standard introductions to form in pop/rock music, see Stephenson 2002, Covach 2005, or Everett 2009.

Return to text

16. "Compound AABA" is the term coined by Covach $(2005,74-5)$ to describe large-scale AABA grouping patterns within verse-chorus songs.

Return to text

17. To accommodate readers, I have transcribed this song according to the traditional method - e.g., Moore (2001, 42), Stephenson $(2002,2)$ - by which the backbeat is assigned to beats 2 and 4 of a $\frac{4}{4}$ meter. As discussed in de Clercq (2016), it would also be possible to transcribe this song as a half-time feel, with measures only half as long as in my transcription.

Return to text

18. Moore (2001, 225), Everett (2009, 145), and Stephan-Robinson (2009, 100-1) imply that refrains do not or cannot occur in chorus sections.

Return to text

19. The term "turnaround" is common within the Nashville community, as found in Riley (2010, 
12). The term "interlude" can be found in the writing of Covach $(2009,370-1)$. "Janus module" is the term introduced by Summach $(2012,54)$, due to the forward- and backward-looking nature of the section. That no standard term exists for the link role may imply that it is not yet a full-fledged concept. But concepts are not necessarily tied to specific words; concepts can exist prior to language coalescing around a particular term, such as is humorously shown in Hall's classic book on sniglets (1984).

Return to text

20. Additional examples from this era in which the title text (or something very similar) overlaps the chorus-link boundary include: at 2:01 in "Every Little Kiss" (Bruce Hornsby and the Range, 1986), at 1:19 in "Now and Forever" (Anne Murray, 1986), at 1:28 in "Stuck With You" (Huey Lewis \& the News, 1986), at 1:29 in "Glory of Love" (Peter Cetera, 1986), at 1:37 in "Here With Me" (REO Speedwagon, 1988), and at 1:41 in "I'll Be There for You" (Bon Jovi, 1988).

Return to text

21. I borrow the term "pump-up" modulation from Doll 2011, who uses it to describe any modulation up by half or whole step, typically occurring near the end of a song.

Return to text

22. The " $\mathrm{B}$ " material in a 32-bar AABA is typically referred to as the "bridge," even if there is some disagreement as to what to call the " $A$ " material (see Covach 2005, 69; Stephenson 2002, 140). In a compound "AABA" form, the "B" group may still be considered "bridge" material. Indeed, Covach implies as much in his description of compound AABA form: "In a compound AABA form, each A section contains at least one verse and a chorus section. . After two presentations of this versechorus unit (A A), a contrasting bridge section occurs (B), followed by a return to some version of the verse-chorus pair (A)" (2009, G-1).

Return to text

23. The phrase "second verse, same as the first" is a reference to the song "I'm Henry VIII, I Am" (Herman's Hermits, 1965), in which the lead singer speaks this text between two strophic passages with identical lyrics.

Return to text

24. In all explanations of form in pop/rock theory, the refrain is framed as material within a section, such as the verse, rather than material that exists at the same hierarchical level as the verse or chorus (Moore 2001, 52; Stephenson 2002, 135; Everett 2009, 144-5).

Return to text

25. Although the chords D and E could imply a tonic of A major, bVI and bVII often act in rock music as subdominant and dominant agents, especially in minor or modal keys. See Biamonte 2010 for a further discussion of harmonic function in rock music.

Return to text

26. As discussed in de Clercq 2016, it is often more useful to compare the form of songs in terms of absolute time than through traditional measure lengths as determined by kick and snare.

Return to text

27. The term "soul dominant" has been used by others (Adams 2015, 10; Spicer 2017, [3]) to refer to a IV chord with scale degree ${ }^{\hat{5}}$ in the bass.

Return to text

28. The "multivalent" analytical method described by Webster (2009) for Classical music is similar to the approach I take in this essay.

Return to text 
29. In this regard, my use of the term "role" parallels the term "formal function" as used by Caplin (1998) to describe form in the music of Haydn, Mozart, and Beethoven.

Return to text

\section{Copyright Statement}

\section{Copyright $@ 2017$ by the Society for Music Theory. All rights reserved.}

[1] Copyrights for individual items published in Music Theory Online (MTO) are held by their authors. Items appearing in MTO may be saved and stored in electronic or paper form, and may be shared among individuals for purposes of scholarly research or discussion, but may not be republished in any form, electronic or print, without prior, written permission from the author(s), and advance notification of the editors of MTO.

[2] Any redistributed form of items published in $M T O$ must include the following information in a form appropriate to the medium in which the items are to appear:

This item appeared in Music Theory Online in [VOLUME \#, ISSUE \#] on [DAY/MONTH/YEAR]. It was authored by [FULL NAME, EMAIL ADDRESS], with whose written permission it is reprinted here.

[3] Libraries may archive issues of MTO in electronic or paper form for public access so long as each issue is stored in its entirety, and no access fee is charged. Exceptions to these requirements must be approved in writing by the editors of MTO, who will act in accordance with the decisions of the Society for Music Theory.

This document and all portions thereof are protected by U.S. and international copyright laws. Material contained herein may be copied and/or distributed for research purposes only.

Prepared by Samuel Reenan, Editorial Assistant

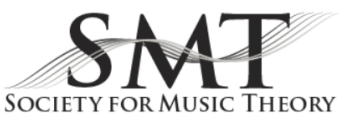

